\title{
EL PRINCIPIO DE IGUALDAD ENTRE LAS PARTES EN EL PROCESO PENAL EN MÉXICO
}

\author{
The principle of equality between the parties to criminal proceedings in Mexico
}

\author{
Rafael SANTACRUZ LIMA*
}

\begin{abstract}
Sumario:
I. Consideraciones iniciales II. La igualdad entre las partes en el proceso penal III. La igualdad entre las partes como respeto a los derechos humanos IV Proceso penal y garantismo V. Conjeturas VI. Bibliografía
\end{abstract}

Resumen: El presente artículo tiene como finalidad realizar un análisis al principio de igualdad entre las partes en el proceso penal, bajo el entendido de que el Ministerio Público, la víctima, el ofendido, el defensor y el imputado, gozan de las mismas prerrogativas y oportunidades para aportar, ofrecer y desahogar las pruebas, y por supuesto, para debatirlas dentro del proceso, de no ser así, se estarían vulnerando sus derechos humanos.

Palabras clave: Igualdad, proceso, garantismo, derechos humanos

\begin{abstract}
The purpose of this article is to analyze the principle of equality between the parties in criminal proceedings, on the understanding that the Public Ministry, the offended, the victim, the defender and the accused, enjoy the same prerogatives and opportunities for provide, offer and release evidence, and of course, to debate them in the process, otherwise they would be violating their human rights.
\end{abstract}

Key words: Equality, process, guarantees, human rights

\section{Consideraciones iniciales}

Los principios del proceso penal - entendido como conceptos o proposiciones de naturaleza axiológica que forman la estructura de las normas- son categorías históricas que surgen en un momento y evolucionan con el desarrollo de la sociedad, los cuales constituyen el eje principal que debe seguir todo enjuiciamiento, con la firme intención de otorgar un máximo de seguridad jurídica y un mínimo de violencia, a todos los sujetos que intervienen en el proceso penal.

De tal forma, en el presente artículo se realiza un estudio a uno de los principios que son de importancia en el proceso penal, el principio de igualdad entre las partes, junto con una pequeña crítica a los supuestos de excepción en México, donde se ve afectado dicho principio, para argumentar el hecho de que todos los sujetos deben gozar de los mismos derechos y oportunidades para aportar, ofrecer y desahogar pruebas, pero más aún, la importancia que tiene

\footnotetext{
* Profesor-investigador de tiempo completo, y líder del Cuerpo Académico Justicia Penal y Seguridad Pública, en la Facultad de Derecho de la Universidad Autónoma del Estado de México (UAEMex). Miembro del Sistema Nacional de Investigadores (Candidato) Correo: rsantacruzl@uaemex.mx
} 
dentro de un proceso penal democrático, que éstas pruebas puedan ser objeto de confrontación y debate. La igualdad entre las partes, en consecuencia, aparece como un pilar importante para garantizar los derechos humanos de los sujetos que intervienen en el proceso penal, con la intención de generar certeza en el enjuiciamiento.

La igualdad requiere, para su existencia en el proceso penal, de un sistema garantista y bajo el cobijo del principio de contradicción, con ello, se busca que los sujetos en el proceso penal cuenten con los medios necesarios para presentar sus respectivas posiciones, pretensiones, $y$ puedan generar con ello, las condiciones de debate, para que puedan ser oídos y vencidos en juicio. Con lo anterior, las partes permitirán articular un proceso dialéctico de valoración de la prueba para conocer la verdad de los hechos a partir de la presentación de pruebas y argumentos de manera equilibrada y bajo las mismas circunstancias. De no contar con dichas circunstancias, se estaría vulnerando dicho principio, y por ende, derechos humanos.

\section{La igualdad entre las partes en el proceso penal}

El término Igualdad (griego, isote, latín, aequitas, aequalitas, francés égalité; alemán, Gleichheit; ingles, equality) se refiere a una relación cualitativa. La igualdad significa correspondencia entre un grupo de diferentes objetos, personas, procesos o circunstancias que tienen las mismas cualidades en por lo menos algún aspecto, pero no en todos, es decir, debe considerarse alguna característica en específico ${ }^{1}$.

De tal suerte que la igualdad, es un valor que requiere ser compatible con otros fines, para ello dependerá de la situación en concreto, por lo que no puede deducirse de ninguna clase de leyes generales ${ }^{2}$. La igualdad, como principio y derecho fundamental, no requiere ser argumentada para que se explique, sino que es el trato desigual el que requiere de argumentos racionales para su justificación, estos argumentos se necesitan para que sean aplicados y no considerados injustos ${ }^{3}$.

Como categoría y concepto axiológico, la igualdad tiene un significado que lleva consigo el hecho de ser incluido en tratados internacionales, textos constitucionales, hasta las normas secundarias. Ahora bien, la igualdad es un concepto que no es exclusivo del derecho penal, en otras palabras, la igualdad es un término amplio y general, es decir, que puede ser abordado desde cualquier rama del derecho.

Como se puede apreciar, de lo anteriormente descrito, la igualdad es un concepto amplio y complejo, por lo tanto puede ser estudiado en diferentes sentidos y objetivos, que no necesariamente obedecen al derecho, sin embargo, para fines del presente artículo trataremos de delimitarlo al aspecto jurisdiccional, en especial, como principio que busca garantizar los derechos de los sujetos procesales dentro del proceso penal.

De este modo, y con la finalidad de enfocarlo al proceso penal, la igualdad entre las partes, ha estado vinculada al concepto de justicia, y para desarrollar las ideas de justicia, vinculadas a la igualdad, contamos con la formulación teórica que se realizó en el siglo XX, con la famosa teoría de la justicia de John Rawls ${ }^{4}$, quien describe que una teoría de justicia no merece

\footnotetext{
1 Pérez, Portilla, Karla (2004), Principio de Igualdad: Alcances y perspectivas, UNAM, México, p. 5.

2 BERlin, Isaiah, Conceptos y categorías, FCE, España, p. 169.

3 Ídem.

4 Gargarella, Roberto (2013), La teorías de la justicia después de Rawls, Un breve manual de filosofía política, Barcelona, Paidós, p. 40.
} 
ser reconocida como tal si permite que las personas resulten beneficiadas o perjudicadas por circunstancias ajenas a su voluntad, esto es, por circunstancias ajenas a su propias elecciones 5 .

Para describir la jurisdicción penal, no puede haber beneficios ni perjuicios para ninguna de las partes - o sujetos - en el proceso penal, porque ello originaría una desigualdad, y por ende, un vicio en la decisión por parte del órgano jurisdiccional. Es por ello, que la igualdad en el proceso penal, constituye un pilar fundamental para la impartición de justicia, sin igualdad, la legitimidad de la decisión se vería afectada ${ }^{6}$.

La igualdad entre las partes, como un principio en el proceso penal, debe entenderse como prerrogativas que deben gozar lo sujeto del procedimiento penal (ministerio público, víctima, ofendido, defensor, imputado), con la finalidad de contar con las mismas oportunidades para aportar, ofrecer, materializar y desahogar las pruebas, y algo importante, para poderlas debatir e impugnarlas ${ }^{7}$. El debate constituye un pilar fundamental para la legitimación de dichas prerogativas.

De tal forma, la igualdad entre las partes, permitirá que las pruebas, los estándares de suficiencia probatoria, los plazos procesales y demás hechos tenidos por probados, se puedan realizar bajo un escenario de garantías de los derechos de las partes, evitando con ello, una mala valoración que repercuta en una resolución de una falsa culpabilidad o inclusive de una falsa absolución (que se puedan considerar igual de graves esas resoluciones que puedan ser falsables) o posiblemente verdaderas (en el mejor de los casos) ${ }^{8}$.

Se puede afirmar que el principio de igualdad entre las partes, requiere del principio de contradicción ${ }^{9}$, ya que el proceso penal, en un sistema acusatorio, está dotado de garantías constitucionales; está presidido por la idea de debate, de controversia, de conflicto de intereses

\footnotetext{
${ }^{5}$ El pensamiento igualitario de Rawls, se ha referido a la distinción entre hechos arbitrarios desde su punto vista moral (hechos ajenos a la responsabilidad de cada uno), y hecho de los cuales uno es plenamente responsable. Ello, para decir que una sociedad justa debe tener, en lo posible, a igualar a las personas en sus circunstancias, de modo tal que lo que ocurra con sus vidas quede bajo su propia responsabilidad. En tal sentido, se puede establecer que, la naturaleza no es justa o injusta con nosotros, lo que es justo o injusto es el modo en que el sistema institucional procesal opera. De ahí surge su afirmación de que la primera virtud de cualquier sistema institucional ha de ser la de su justicia por medio de la igualdad.

${ }^{6}$ En el proceso penal, existen dos principios que tiene como justificación la igualdad, que son: igualdad ante la ley, e igualdad entre las partes. El primero, igualdad ante la ley, que pareciera confundirse con el tema que nos ocupa, pero cuya diferencia reside en una correcta objetividad judicial, es decir, evitar que alguno de los sujetos en el proceso penal, pueda ser discriminado por motivos de origen étnico o nacional, género, edad, discapacidad, condición social, condición de salud, religión, opinión, preferencia sexual, estado civil o cualquier otra que atente contra la dignidad humana y tenga por objeto anular o menoscabar los derechos y las libertades de las personas, en otras palabras, que el enjuiciamiento debe estar libre de prejuicios.

7 En este sentido, el Código Nacional de Procedimientos Penales, nos expresa en su artículo 11 que: Se garantiza a las partes, en condiciones de igualdad, el pleno e irrestricto ejercicio de los derechos previstos en la Constitución, los Tratados y las leyes que de ellos emanen.

8 Hernández Aguirre, Christian Norberto (2015),"Reflexiones sobre el principio de contradicción en el proceso penal acusatoria", Revista Prospectiva, Universidad Autónoma del Estado de México, No 5, p. 58.

9 Que se resume en el vocablo latino auditar et altera pars (óigase a la otra parte), es uno de los principios generales del derecho que tiene antecedentes más remotos. Aparece en textos de escritores griegos como Eurípides, quien en las Heraclidas se preguntaba: ¿Quién podría decidir una causa sin haber escuchado a las dos partes?; o como Aristófanes, quien en Las avispas afirmaba: Sabio es verdad quien dijo: no se debe juzgar antes de escuchar a las dos partes. Se atribuye a Foclídes de Amileto la siguiente frase: antes de haber oído a una y otra parte, no se debe dar sentencia sobre su litigio.
} 
y lucha de contrarios. Por lo que se puede aducir, que el proceso es una actividad donde las partes tienen por objetivo velar por los intereses que representan ${ }^{10}$.

Con el proceso penal, se busca articular un proceso dialéctico de valoración de la prueba para conocer la verdad de los hechos a partir de la presentación de pruebas y argumentos de manera equilibrada y en la misma igualdad de circunstancias ${ }^{11}$. Con ello se buscará, que exista un equilibrio de los sujetos en el proceso penal, y el respeto a sus derechos y prerrogativas.

En este sentido, el proceso penal no puede entenderse como un monólogo del juez, sino como un diálogo abierto, entre los diversos intervinientes en su calidad de partes, sujeto a acciones y reacciones, a ataques y contraataques. Por estos motivos se le ha denominado también como de bilateralidad, de controversia o de carácter dialéctico del proceso ${ }^{12}$. Con ello podemos afirmar, que en un sistema inquisitivo jamás se lograría dicha dialéctica.

Por lo tanto, para que la igualdad se pueda llevar a cabo en el proceso penal, se requiere dela aplicación de una correcta contradicción, es decir, que los sujetos en el proceso penal dispongan de todos los medios necesarios para presentar sus respectivas posiciones, pretensiones mediante una correcta preservación del derecho de audiencia, para que los sujetos tengan la oportunidad de ser oído y vencido en juicio ${ }^{13}$. Con lo anterior, las partes permitirán articular un proceso dialéctico de valoración de la prueba para conocer la verdad de los hechos a partir de la presentación de pruebas y argumentos de manera equilibrada y en igualdad de circunstancias entre los sujetos.

Se requiere entonces, que el órgano jurisdiccional tenga conocimiento de los sujetos procesales, así como de todas pruebas practicadas y de la forma que se aportaron al proceso, lo anterior evitará realizar medios de convicción secretos y mecanismos indebidos que no sean objeto de la controversia. De tal manera que, cada sujeto procesal, pueda confrontar y debatir los medios de prueba, bajo las mismas oportunidades y circunstancias ${ }^{14}$, y se logre con ello, una correcta igualdad entre las partes.

\section{La igualdad como respeto a los derechos humanos}

La dignidad del ser humano, la importancia de éste como persona y el respeto a sus derechos, han sido motivo de una búsqueda permanente en la ciencia del derecho - concretamente del derecho penal- que proviene desde la antigüedad, cobrando importancia en la ilustración, y continúa hasta nuestros días ${ }^{15}$.

En este sentido, los derechos humanos, que se encuentran reconocidos y establecidos en la Constitución y los Tratados Internacionales, necesitan para su plena eficacia una serie de instrumentos normativos -garantías- que permitan su eficaz cumplimiento en el sistema jurídico $^{16}$. Por lo tanto, dentro del proceso penal, o enjuiciamiento, se busca otorgar un máximo de

\footnotetext{
${ }^{10}$ Ídem.

${ }^{11}$ Baytelman A. Andrés y Duce J. Mauricio (2009), Litigación penal juicio oral y prueba, $2^{\mathrm{a}}$ ed. México, Fondo de Cultura Económica, p. 19.

${ }^{12}$ Hernández, op.cit. nota 8, p. 67.

13 Ídem.

14 De modo entonces, la igualdad entre las partes necesita de la aplicación del principio de inmediación, es decir, presencia del órgano jurisdiccional, así como de las partes que deban de intervenir en el proceso; y del principio de contradicción, para que las partes puedan conocer, controvertir o confrontar los medios de prueba, así como oponerse a las peticiones y alegatos de la otra parte.

15 Zaffaroni, Eugenio Raúl (2009), El humanismo en el derecho penal, México, Ubijus, p. 7.

${ }^{16}$ Moreno Melo, Manuel (2015), Principios Constitucionales de Derecho Penal. Su aplicación en el sistema acusatorio (teoría, práctica y jurisprudencia), México, Ubijus, p. 77.
} 
seguridad jurídica y un mínimo de violencia, con la intención de proteger los derechos humanos de los sujetos del proceso penal.

La igualdad entre las partes, como principio en el proceso penal, debe conducirse a favor de los derechos humanos, para ello es necesario una integración y mayor participación de los sujetos que intervienen en el proceso penal, así como el ejercicio para poder debatir durante el proceso penal, con la intención de llegar al objetivo que se propone el proceso, la actuación receptiva de órgano jurisdiccional con respecto a los sujetos procesales, en la búsqueda de una verdad aproximada ${ }^{17}$.

Para comenzar a analizar el respeto a los derechos humanos y el principio de igualdad en el proceso penal en nuestro país, es conveniente desarrollar lo siguiente: como sabemos en México, a partir del dieciocho de junio de dos mil ocho, se da un cambio de modelo a la justicia penal, al establecerse un modelo acusatorio-adversarial. Con ello se desarrollan principios como la publicidad, continuidad, inmediación, concentración y la contradicción, principios que buscan darle un sentido más humano al proceso penal, y con ello, lograr que el proceso penal tengan un sentido más garantista.

De igual manera, la reforma del dieciocho de junio de dos mil ocho, también fue la fuente de legitimación para que el cinco de marzo de dos mil catorce, se publicara en el Diario Oficial de la Federación, el Código Nacional de Procedimientos Penales, mismo que estableció en su artículo once el principio de igualdad entre las partes, como uno de los principios rectores del proceso penal en México.

También, dicha reforma constitucional estableció de forma excepcional, supuestos donde no se aplican estos principios de justicia penal. Dichos supuestos, son propiciados por la delincuencia organizada, y por aquellos delitos graves, que vayan en contra de la seguridad de la nación. Desde luego que ello genera, de manera amplia una incertidumbre y falta de credibilidad al debido proceso penal, y de manera muy específica, ausencia de respeto a los derechos humanos ${ }^{18}$.

De tal forma, que no es posible asumir que en México se cuenta con un modelo del todo garantista, y por ende, que respete en su totalidad los derechos humanos de sus habitantes. Un ejemplo de ello, es la fracción tercera del artículo veinte constitucional, que estableció como derecho del imputado el ser informado de los derechos que le asisten. Sin embargo, quienes sean acusados por delincuencia organizada no podrán conocer el nombre y datos de quien acusa. Por otra parte, la fracción quinta en su párrafo segundo, señala que en tratándose de delincuencia organizada, las actuaciones realizadas en la fase de investigación podrán tener valor probatorio ${ }^{19}$.

Sin embargo, es irónico que nuestro proceso penal tenga como base principios reguladores del proceso penal, pero que contemple la posibilidad de no aplicarlos en ciertos supuestos. Lo anterior, y para desarrollar el tema que nos ocupa - la igualdad entre las partes - podemos afirmar que en los supuestos de delincuencia organizada, y en aquellos delitos graves, se genera una contradiccional principio de igualdad, por no contar con las mismas oportunidades dentro del proceso para ofrecer y desahogar pruebas.

En tal sentido, surgen las siguientes interrogantes: ¿No acaso la reforma constitucional había establecido la contradicción como un principio elemental del nuevo sistema de justicia penal? ¿Cómo defenderse de un acusador anónimo? Si desaparecen estos principios, no podrá darse

\footnotetext{
17 HernándeZ, op. cit. nota 8, p. 61.

${ }^{18}$ Santacruz Lima, Rafael, La prueba en el sistema penal de excepción, Porrúa-Print, 2015, p. 114.

${ }^{19}$ Coaña, Be, Luis, México: ¿Garantismo o Derecho Penal del Enemigo?, México, Ubijus, 2014, p. 90.
} 
una correcta igualdad entre las partes. Resulta paradójico que la Constitución, en el discurso, pretenda asegurar y garantizar derechos, si en la realidad pueden verse disminuidos ${ }^{20}$.

En el sistema de justicia penal, dentro del discurso legitimador, solamente valdrá lo que se reproduzca en un juicio oral, público y con el juez y las partes presentes, sin embargo, también se autoriza en la Constitución que las actuaciones realizadas en la fase de investigación tengan valor probatorio, lo que resulta criticable aún y cuando se trate de delincuencia organizada, pues ya no podemos hablar entonces de un sistema penal que respete derechos humanos, ya que es evidente que no cumple con los parámetros mínimos de igualdad entre las partes.

En tal sentido, se puede aducir que la palabra contradicción con relación a la igualdad entre las partes, significa que la parte contraria a quien se opone una prueba, debe contar con la oportunidad procesal para conocerla y discutirla, es decir, que debe de llevarse a la causa que la generó, con conocimiento y audiencia de las partes. De tal forma, la prueba, en los supuestos de delincuencia organizada, es contraria a los derechos humanos y a los principios rectores del sistema acusatorio adversarial, por no respeta la contradicción e igualdad entre las partes ${ }^{21}$.

Por lo tanto, podemos percibir que de manera específica, en el proceso penal en México, no se desarrolla una igualdad entre las partes, y se orienta al menoscabo de los derechos humanos, de las personas que sean acusadas de pertenecer a la delincuencia organizada y, en ese sentido $^{22}$, y tomado en consideración, la corrupción y deficiencias que pueden presentarse en la investigación, cualquier persona podría caber en éste supuesto. En tal sentido, se genera una falta de seguridad jurídica.

\section{Proceso penal y garantismo}

El garantismo penal, primero que todo, representa una ideología que surgió en la cultura jurídica italiana de mediados de los años setenta del siglo pasado. En este sentido, el garantismo aparece como una forma de tutela del derecho de la vida, de integridad y de libertad, y en general, al respeto a la dignidad humana y a los derechos humanos, frente al poder punitivo que detenta el Estado ${ }^{23}$.

Uno de los máximos exponentes del garantismo penal es, sin lugar a dudas, Luigi Ferrajoli, quien toma como fundamento a la razón en el derecho, es decir, que las actuaciones en el ámbito jurisdiccional deben estar sustentadas y fundadas en cuestiones cognoscitivas. De modo tal, que el sentido opuesto al garantismo es, el sistema penal inquisitivo o autoritario, cuya característica es que las funciones de investigar, acusar y juzgar están concentradas en una misma autoridad. Esta concentración puede dar lugar a diversos problemas para la administración de justicia $^{24}$.

De tal manera que, la oposición hasta ahora ilustrada entre garantismo y autoritarismo en el derecho penal corresponde, pues, a una alternativa de dos puntos de vista totalmente distintos: comprobación y valoración, entre prueba e inquisición, entre razón y voluntad, entre verdad y

\footnotetext{
${ }^{20}$ Ídem.

${ }^{21}$ Es aquí donde cobra importancia el discurso de Luigi Ferrajoli que establece: El verdadero campo de prueba de los derechos fundamentales, es el derecho penal

22 CoAÑA, op. cit. nota 19, pp. 90 y 91.

${ }^{23}$ Ferrajoli, Luigi (2008), Democracia y Garantismo, (coord.) de Miguel Carbonell, Madrid, Trotta, p. 61.

${ }^{24}$ Carbonell, Miguel y Ochoa Reza, Enrique (2008), ¿Qué son y para qué sirven los juicios orales?, México, Porrúa, p. 29.
} 
potestad. Si una justicia penal completamente con verdad constituye una utopía, una justicia penal sin verdad equivale a un sistema de arbitrariedad ${ }^{25}$.

Lo que nos lleva a establecer que un elemento de todo sistema penal garantista es la prueba, como eje rector de mayor importancia para la búsqueda de la verdad. Por lo tanto, en el desarrollo de la actividad probatoria, en el sistema garantista, debe darse en una circunstancia de igualdad entre las partes, de lo contrario, la actividad jurisdiccional puede caer en un voluntarismo que tenga como sustento a la inquisición y a la arbitrariedad ${ }^{26}$.

De tal forma que, para el aspecto jurisdiccional en materia penal, ninguna mayoría, por aplastante que sea, puede hacer legítima la condena de un inocente o convalidar un error cometido en perjuicio de un ciudadano. Y ningún consenso político -del parlamento, de la prensa, de los partidos o de la opinión pública- puede sustituir la falta de prueba de una acusación. En un sistema garantista, el consenso mayoritario o la investidura representativa del juez no agrega nada a la legitimidad de la jurisdicción, pues ni la voluntad o interés general ni ningún otro principio de autoridad pueden convertir en verdadero lo que es falso, o viceversa ${ }^{27}$.

Por lo tanto, el garantismo penal, tiene un rol muy importante dentro de la igualdad entre las partes, ya que busca por medio de la prueba la confrontación, es decir, la refutación y verificación de las partes, sea el caso de cada una de ellas; de no lograrse dicha confrontación y refutación, se estaría bajo el modelo de un sistema inquisitivo, y por ende, falto de igualdad entre las partes.

En relación a lo anterior, en el proceso penal en México, para poner en duda a la confrontación, como elemento central del sistema penal garantista, la prueba anticipada es un ejemplo de como en nuestro sistema de justicia penal, se establecen aspectos contrarios a la igualdad entre las partes, y con ello, a los postulados del garantismo.

Lo anterior, nos invita a realizar un análisis de un caso práctico, para poder soportar dicha aseveración:

En la audiencia para el desahogo de prueba anticipada, del expediente 708/2015, por el delito de secuestro en agravio de persona del sexo femenino de identidad reservada, celebrada el o8 de junio de 2015, en la sala 2 del Juzgado de control del Distrito Judicial de Toluca, residente en Almoloya. La petición por parte del Ministerio Público, para la celebración de la audiencia para el desahogo de la prueba anticipada, se solicitó bajo los siguientes elementos: a) La víctima cuenta con nacionalidad de los Estados Unidos de Norte América; b) Un certificado médico donde se describe estado gravidez de la víctima; c) Un boleto de avión, donde señala el nombre de la víctima, y fecha de vuelo con destino a los Estados Unidos de Norte América, d) Y la petición del consulado de los Estados Unidos, para que la víctima pueda dar a luz en dicho país. Con tales elementos el Juez de control aceptó el desahogo de la prueba anticipa$d a^{28}$.

Para poder analizar este caso práctico, el artículo 304 del Código Nacional de Procedimientos Penales, nos establece que ${ }^{29}$ :

\footnotetext{
${ }^{25}$ Ferrajoli, Luigi (2001), Derecho y Razón. Teoría del Garantismo Penal, Madrid, Trotta, $5^{\text {a }}$ ed. p. 45.

${ }^{26}$ Así, podemos mencionar que existen entonces, en el sistema garantista, dos tipos de garantías: las garantías penales (se refiere al delito) y las procesales (se refiere al proceso). Lo que respecta a la garantías penales, éstas se orientan a minimizar los delitos, es decir, a reducir al máximo lo que el Poder legislativo puede castigar, en tanto que las garantías procesales se orientan a minimizar el Poder Judicial, es decir, a reducir al máximo los márgenes de arbitrio de los jueces.

27 Ferrajoli, op. cit. nota 23, p. 105.

${ }^{28}$ SAntacruz, op. cit. nota 18, p. 122.

${ }^{29}$ Ídem.
} 
La prueba anticipada podrá ser solicitada por alguna de las partes, quienes deberán expresar las razones por las cuales el acto se debe realizar con anticipación a la audiencia de juicio a la que se pretende desahogar y se torna indispensable en virtud de que se estime probable que algún testigo no podrá concurrir a la audiencia de juicio, por vivir en el extranjero, por existir motivo que hiciere temer su muerte, o por su estado de salud o incapacidad física o mental que le impidiese declarar.

Por lo tanto, si analizamos la solicitud por parte del ministerio público, la prueba anticipada debe ser solicitada por alguna de las partes, en este caso, se cumple con dicho requisito, sin embargo, cuando establece que deben expresarse las razones, el ministerio público, no dio las razones justificadas para el desahogo de dicha prueba, es más, consideramos que el juez de control, no debió haber aceptado el desahogo de dicha prueba, toda vez, que la víctima no cuenta con sus domicilio en el extranjero, y el estado de gravidez no imposibilita a la víctima para que pueda concurrir a la audiencia de juicio a declarar con posterioridad.

Y si bien es cierto, que el artículo 305 del Código Nacional de Procedimientos Penales, establece que [...] El órgano jurisdiccional citará a audiencia a todos los que tengan derecho a la audiencia de juicio oral, $y$ "valorara", la posibilidad de que la prueba por anticipar no pueda ser desahogada en la audiencia final [...] también es cierto, que se desahogará y valorará en una etapa distinta al juicio oral, y con un juez diferente al enjuiciamiento.

En ese tenor de ideas, el Código Nacional de Procedimientos Penales no define el concepto de desahogo de la prueba y con ese concepto confunde desahogo previo al referirse a la prueba anticipada, por lo tanto, la prueba se presenta como una forma diferente de ofrecerse, desahogarse y valorarse en audiencia ajena a la etapa de juicio oral ${ }^{30}$.

Lo anterior, nos permite establecer que la prueba anticipada, vulnera el principio de igualdad entre las partes, porque no se realiza bajo las mismas circunstancias y prerrogativas que permitan a los sujetos en el proceso, contar con las oportunidades para aportar, ofrecer, materializar desahogar, y por supuesto, debatir las pruebas.

En la justicia penal, tampoco la inclinación o favoritismo que pueda tener el órgano jurisdiccional, por alguna de las partes -o sujetos del proceso- puede ser factor para influir dentro de la actividad del juez, ya que entonces no existirían las condiciones necesarias para desarrollo de la prueba, y el debate que pueda generarse en torno a las mismas. El juez debe actuar de manera imparcial, y con ello, genera un clima de igualdad entre las partes.

En este sentido, el ejemplo que hemos analizado, no cumple con dicha confrontación. La prueba es un elemento esencial en el sistema penal garantista, proceso penal o enjuiciamiento, buscando la confrontación, es decir, la refutación y verificación de las partes, para poder lograr con ello, una correcta igualdad entre las partes; de no ser así, se estaría hablando de un sistema inquisitivo y autoritario ${ }^{31}$.

\section{Conjeturas}

A) A manera de conjetura, podemos establecer que, la igualdad entre las partes, como un principio en el proceso penal, debe entenderse como prerrogativas que gozan los sujetos del procedimiento penal, con la finalidad de que puedan contar con las mismas oportunidades para aportar, ofrecer, materializar y desahogar las pruebas, y algo importante, para poderlas debatir e impugnarlas.

\footnotetext{
${ }^{30}$ Es decir, aún cuando la prueba anticipada ingrese al juicio como acta, como registro o como video, se incorpora como si fuera desahogada en juico, poniendo en evidencia la falta de contradicción e inmediación.

${ }^{31}$ Santacruz, op. cit. nota 18, p. 167. 
B) El proceso penal debe tener, como uno de sus objetivos más importantes, el respeto de los derechos humanos de las personas que interviene en el enjuiciamiento, ello originará las condiciones para que exista una correcta igualdad entre las partes.

C) El proceso penal en México, no presenta en su generalidad la aplicación del principio de igualdad entre las partes, en especial, en aquellas personas que son acusadas de pertenecer a la delincuencia organizada, porque como vimos en el presente artículo, no se cumple con las mismas oportunidades para aportar, ofrecer, materializar y desahogar las pruebas, y desde luego, para debatirlas. Por lo tanto, el proceso penal en México, no se genera una correcta igualdad, y si, una falta de garantías y violación a los derechos humanos de los sujetos en el enjuiciamiento.

D) En este sentido, se propone que cuando se traté de delincuencia organizada, se deba conocer la información de quien acusa y por qué, y las actuaciones realizadas en etapa de investigación, como la prueba anticipada, deban tener valor probatorio, siempre y cuando puedan ser confrontadas y debatidas en la audiencia final de juicio.

\section{Bibliografía}

Agambel, Giorgio (2003), Estado de Excepción, Adriana Hidalgo Editora, Buenos Aires.

Baytelman A. Andrés y Duce J. Mauricio (2009), Litigación penal juicio oral y prueba, $2^{\mathrm{a}}$ ed., México, Fondo de Cultura Económica.

Carbonell, Miguel y Ochoa Reza, Enrique (2008), ¿Qué son y para qué sirven los juicios orales?, Porrúa, México.

Coaña Be, Luis (2014), México: ¿Garantismo o Derecho Penal del Enemigo? Ubijus, México.

Despooy, Leonardo (1999), Los derechos humanos y los estados de excepción, Instituto de Investigaciones Jurídicas-UNAM.

Fernandez Carrasquilla, Juan (2004), Derecho Penal Liberal de Hoy, ${ }^{a}$ ed. Ediciones Jurídicas Gustavo Ibáñez, Bogotá.

Ferrajoli, Luigi (2008), "Democracia y Garantismo" (coord.) de Miguel Carbonell, Trotta, Madrid.

(2001), Derecho y Razón. Teoría del Garantismo Penal, 5 a ed. Trotta, Madrid.

(2001), “Derechos y garantías” La ley del más débil. $2^{\mathrm{a}}$ ed. Trotta, Madrid.

Gargarella, Roberto (2013), La teorías de la justicia después de Rawls, Un breve manual de filosofía política”, Paidós, Barcelona.

Hernández Aguirre, Christian Norberto (2015), Reflexiones sobre el principio de contradicción en el proceso penal acusatoria, Revista Prospectiva, Universidad Autónoma del Estado de México, no. 5.

Jakobs, Günther y Cancio Meliá (2003), Derecho Penal del enemigo, Madrid, Civitas. 
Jаковs, Günther (2001), Criminalización en el estadio previo a la lesión de un bien jurídico, Estudios de Derecho Penal, Traducción por Peñaranda Ramos, E. Suárez Gonzalez, Cancio Meliá., Civitas, Madrid.

Moreno Melo, Manuel (2015), Principios Constitucionales de Derecho Penal. Su aplicación en el sistema acusatorio (teoría, práctica y jurisprudencia), México, Ubijus.

Montero Aroca, Juan (2001), Principios del Proceso Penal. Una explicación basada en la razón, Valencia, Tirant lo Blanch.

PÉrez Portilla, Karla (2004), Principio de Igualdad: Alcances y perspectivas, UNAM, México.

Roxin, Claus (2014), De la Dictadura a la Democracia: Tendencias de Desarrollo en el derecho Penal y Procesal Penal Alemán, Ubijus, México.

Santacruz Lima, Rafael (2015), "La prueba en el sistema penal de excepción”, Porrúa-Print, México.

(2013), "La prueba como elemento en un sistema penal garantista", Revista Ciencia Jurídica, número 3, México, Universidad de Guanajuato.

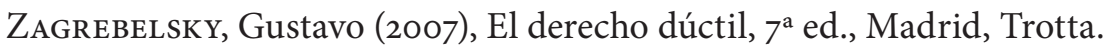

Zaffaroni, Eugenio Raúl (2009), El humanismo en el derecho Penal, Ubijus, México. 